\title{
A Survey Exploring PMS Awareness Trends in Indian Women and a Review of Ways to Harmonize Psycho - Physiological Stress of Premenstrual Syndrome Practicing Yoga Asanas
}

\author{
Chandana Eswar ${ }^{1 *}$
}

\section{ABSTRACT}

Background: Menstruation has been considered as a taboo which made it difficult for women to discuss and voice out their concerns, creating a void in understanding the vitality of menstruation for a healthy womanhood. Purpose of the Study: To investigate level of awareness on PMS among educated women in Indian society and to communicate that it is time that women accept and discuss about menstruation as a natural process, and indulge in psycho-physiological activities such as yoga to learn to manage such conditions. Methodology: A survey was conducted on 305 females aged between 14-31 years. The subjects were asked to write what do they understand by PMS and their level of awareness was assessed based on the responses provided. Results \& Findings: Most of the subjects were not aware of PMS, very few gave either an inappropriate or a correct answer. Conclusion: It has never been ok to speak about menstruation in India. The lack of awareness leads to lack of hygiene and lowers the confidence level in women. Yoga plays a vital role by making it convenient for women to harmonise the psycho-physiological trauma before, during and after menstruation. It high time that we in Indian accept menstruation as a sign of good health and not a curse and it is ok to talk about it.

Keywords: Premenstrual Syndrome (PMS),Taboo, Menstruation \& Yoga, Menstrual Awareness.

A look at major religions of the world shows that, without exception, they have placed restrictions on menstruating women. Judaism, Christianity, Islam, Hinduism, and Buddhism have all made statements about menstruation and its negative effect on women, leading to prohibitions about physical intimacy, cooking, attending places of worship, and sometimes requiring women to live separately from men at this time. Yet there are many religions which, to this day, hold primitive ideas and beliefs regarding this common phenomenon. In India as well menstruation has been considered as a taboo which made it difficult for women to discuss and voice out their concerns, creating a void in understanding the vitality of menstruation for a healthy womanhood.

\footnotetext{
${ }^{1}$ Research Scholar, Bangalore University, Bangalore

*Responding Author

(C) 2016 I C Eswar; licensee IJIP. This is an Open Access Research distributed under the terms of the Creative Commons Attribution License (http://creativecommons.org/licenses/by/2.0), which permits unrestricted use, distribution, and reproduction in any Medium, provided the original work is properly cited.
} 


\section{A Survey Exploring PMS Awareness Trends in Indian Women and a Review of Ways to Harmonize Psycho - Physiological Stress of Premenstrual Syndrome Practicing Yoga Asanas}

\section{What is Menstruation and it's Phases?}

Menstruation is a natural monthly cycle associated with reproduction in humans and other mammals during which vaginal discharge and psycho-physiological discomfort occurs. The discharge consists of blood and cells which sheds from the lining of the uterus. The bleeding can last from two to seven days and signifies that no conception has taken place. The main hormones involved in controlling menstruation are estrogen and progesterone. Menstruation is experienced by women between puberty and menopause and can start between the age of 8 and 18 and last until ages 40 to 60 years. The menstrual cycle on an average is about 28 days, though it can vary considerably from one individual to another.

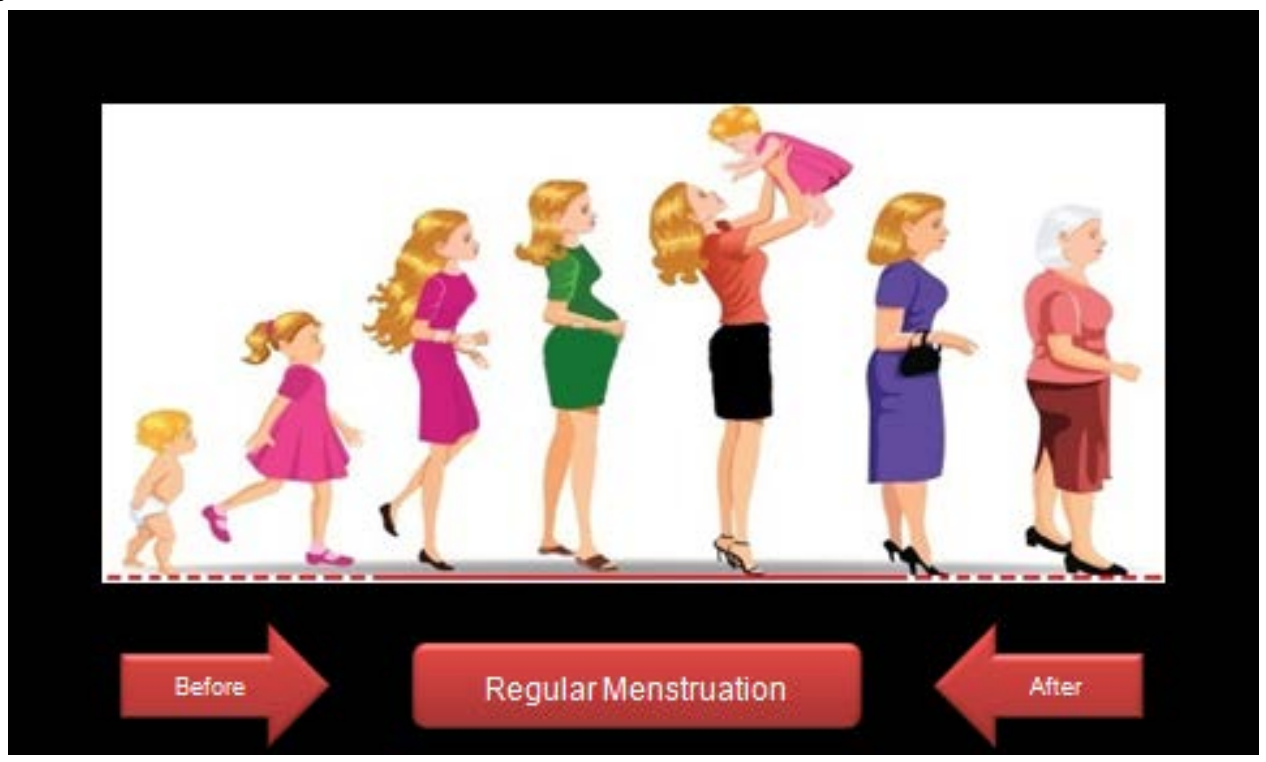

\section{Four Phases of Menstrual Cycle}

The menstrual cycle can be divided into four different phases - bleeding phase, follicular phase, ovulation and the luteal phase. Each phase of the menstrual cycle has a different function and are regulated by several hormones, which can explain the variations in cycle length.

\section{Bleeding phase}

The bleeding phase lasts from the first day of the period to the last day of the period. During this phase the endometrium (lining of the uterus) layers shed as menstruation and an egg starts maturing in the ovary.

\section{Follicular phase}

The follicular phase lasts from the last day of the period to the day of ovulation. During this phase, the body prepares itself to accept and support a pregnancy. The endometrium grows and thickens, and the vaginal environment also changes in order to become more sperm friendly. In the ovaries the egg/ovule matures and develops. 


\section{A Survey Exploring PMS Awareness Trends in Indian Women and a Review of Ways to Harmonize Psycho - Physiological Stress of Premenstrual Syndrome Practicing Yoga Asanas}

\section{Ovulation}

Ovulation is the key event of the menstrual cycle. In each cycle, only one egg/ovule is released and can only be fertilized for up to 48 hours. It is important to accurately identify when the ovulation begins if trying for a baby in order to maximize your chances of getting pregnant.

\section{Luteal phase}

The luteal phase is the final phase of the menstrual cycle and lasts from the day of ovulation to the last day before the next period. It is also the phase where the PMS start to occur. If pregnancy occurs, the embryo will implant itself in the endometrium during this phase if not, it starts to break down and is eventually sloughed off: this is menstruation.

\section{What is Premenstrual Syndrome?}

Premenstrual Syndrome (PMS) involves a variety of emotional symptoms, with or without physical symptoms tied to a woman's menstrual cycle, also called as premenstrual tension or PMT. Medical definitions of PMS are limited to a consistent pattern of emotional and physical symptoms occurring only during the luteal phase of the menstrual cycle that are of "sufficient severity to interfere with certain aspects of life". The specific emotional and physical symptoms attributable to PMS vary from woman to woman, but each individual woman's pattern of symptoms is predictable, generally occurs around seven days prior to the start of the menstrual period, and vanishes either shortly before or shortly after the start of menstrual flow. Two to ten percent of women have significant premenstrual symptoms that are separate from the normal discomfort associated with menstruation in healthy women. Though bothersome, these symptoms are usually not severe enough to interrupt a normal lifestyle. Most women who experience PMS symptoms cope with them at home and very few may seek medical care for any severities. These symptoms affect the following: Mood: Anxiety (nervousness, mood swings, irritability, depression, forgetfulness, confusion, insomnia, hostility), Behavior (Cravings for sweets, increased eating, crying, poor concentration, sensitivity to noise, changes in alcohol tolerance), Physical functions (Headache, heart palpitations, fatigue, dizziness, weight gain, bloating, breast swelling and tenderness, constipation, or diarrhea)

\section{General Practices used to Harmonize PMS}

Cultures across the world view the monthly periods differently. Women across the world cope differently from warm water bags to comfort the piercing cramps, to gentle rubs to ease the fatigued back. It's something that remains an inevitable part of womanhood. Some of the practices also include home remedies, medicines, physical activities, diet etc. e.g. indulging in at least 20 to 30 minutes of aerobic exercise daily throughout the month. If an individual tries to exercise to the point of perspiration it lowers the level of free-circulating estrogen present in the system. Exercise is both a stress reliever and mood enhancer, because it boosts the body's natural painkilling endorphins while also relaxing the muscles. Another such practice can be eating less salt throughout the month, and especially in the week before period. With more salt comes 


\section{A Survey Exploring PMS Awareness Trends in Indian Women and a Review of Ways to Harmonize Psycho - Physiological Stress of Premenstrual Syndrome Practicing Yoga Asanas}

increased fluid retention, hence more bloating and also high-fiber foods help to escort surplus estrogen out of the body; loading up on whole grains like barley, oats, and whole-grain breads; vegetables; and beans, drink more water, cut out on cravings for sweets when PMSing.

\section{Yoga Asanas and PMS}

Yoga is a 5000 year old Indian body of knowledge. Though many think of yoga only as a physical exercise where people twist, turn, stretch, and breathe in the most complex ways, these are actually only the most superficial aspect of this profound science of unfolding the infinite potentials of the human mind and soul. Yoga is a physical, mental, and spiritual practice or discipline that aims to transform body and mind. a part of which, including breath control, simple meditation, and the adoption of specific bodily postures, is widely practiced for health and relaxation.

There are simple ways to ease the physical changes and psychological swings. Yoga and meditation help in relaxing the body and mind. It helps to harmonize the left and right hemispheres of the brain, which correlate to the logical and emotional sides of one's personality.

There are proven benefits of yoga for PMS and menstrual pain. Several yoga asanas (positions) are proven to ease menstrual pain. It can also help the mind and body adapt to stress, anxiety and depression, making one feel relaxed and calm. It is best to practice gentle postures that help assuage the discomfort. Meditation allows the mind to relax and subsides any emotion and the general postures help to ease specific aches and some breathing techniques which prepares an individual to cope efficiently with their monthly cycles. Some of the asanas that help reducing the effects of PMS are:

\section{Cat pose/ B id a las a a}

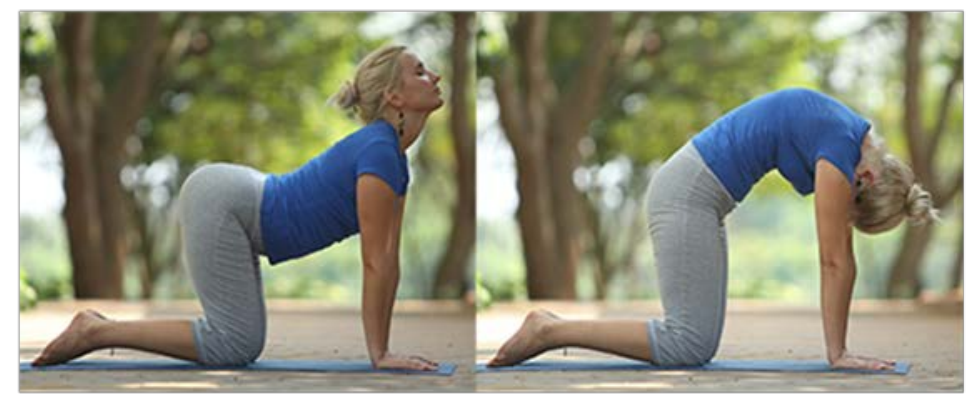

Also called marjari asan, this posture tones and relaxes the spine and abdomen. 


\section{Cobra pose/ B h u jangas a n a}

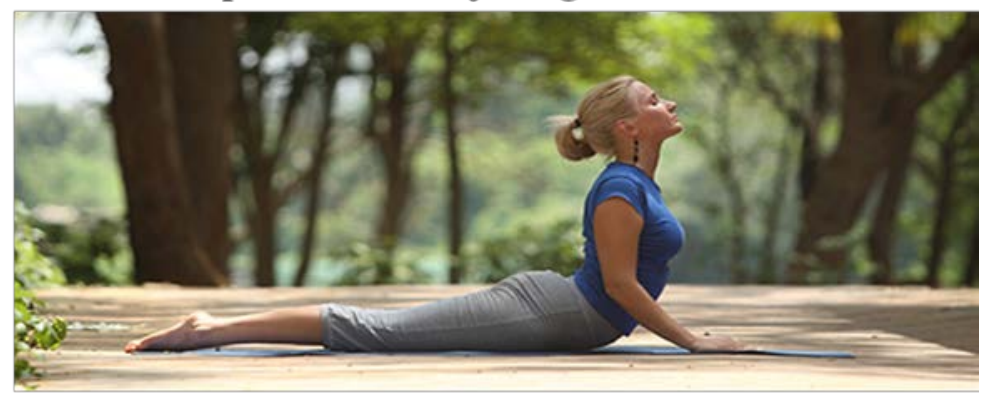

Great for blood circulation and relaxing the back.

Fish pose/Matsyas a a

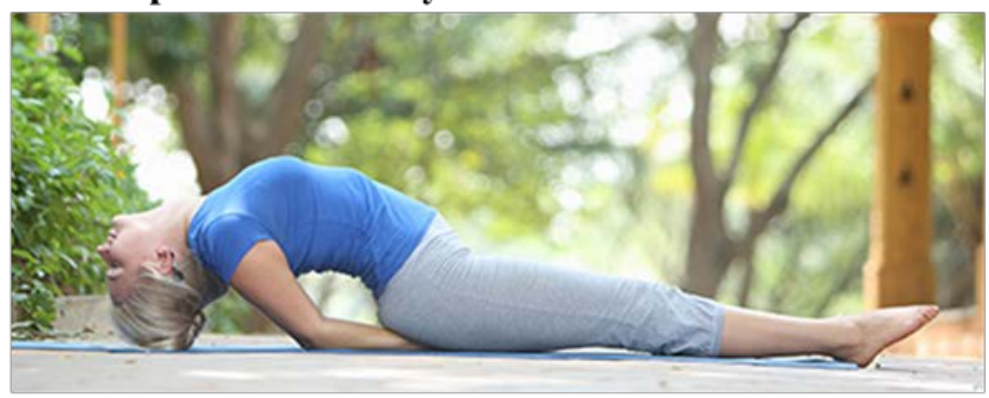

Stretches the chest and neck and great for releasing tension

\section{Child pose/ B a l a s a n a}

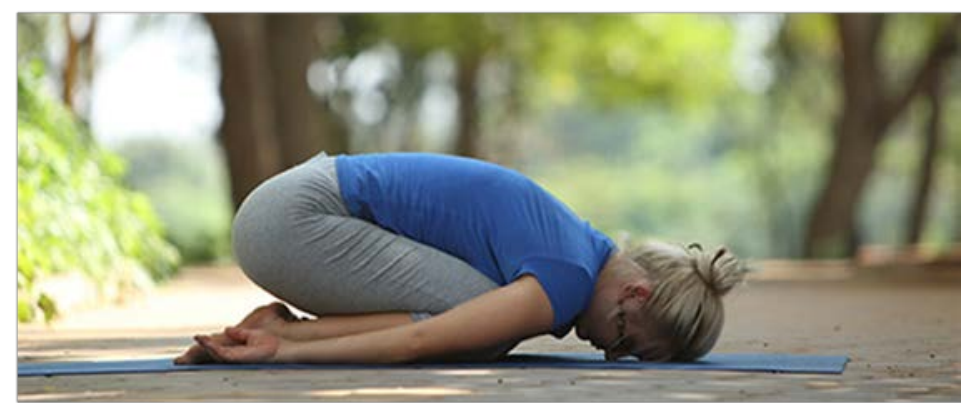

Calms the nervous system and soothes the back. 
B ow pose/Dhanursan a

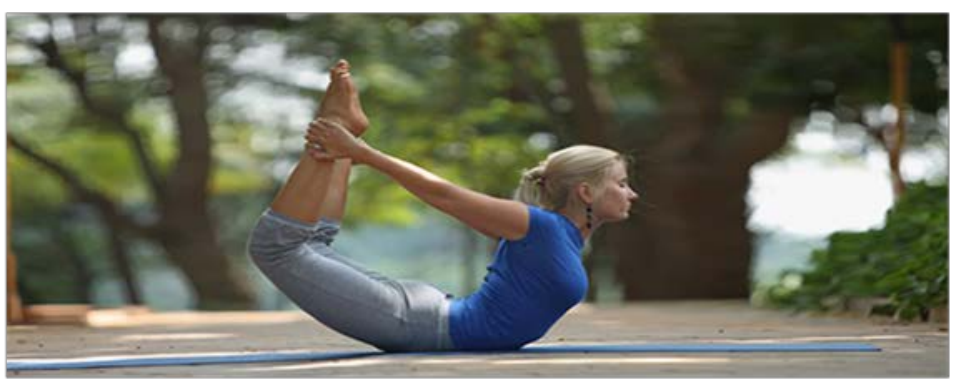

It is ideal for menstrual discomfort and removes fatigue.

Corpse pos e/ Sh avas a a

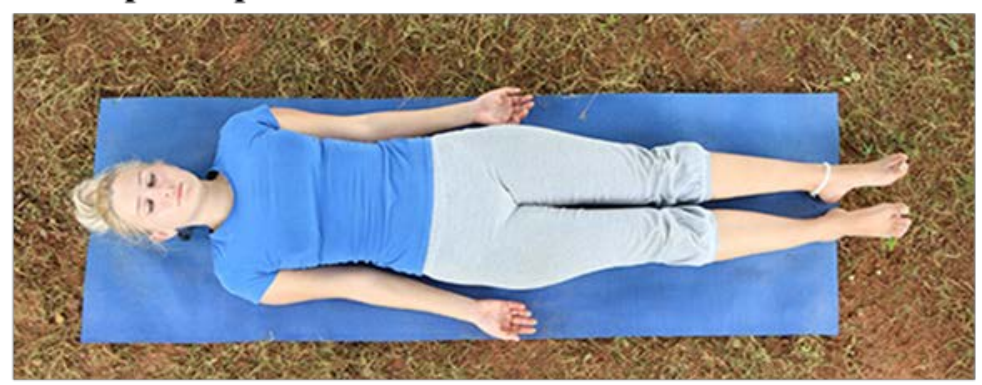

This posture brings a deep, meditative state of rest, which may help in the repair of tissues and cells, and in releasing stress.

The other asanas that can also been practiced are: Wind relieving pose/Pavanamuktasana, Crocodile pose/Makarasana, Standing- forward bend/Padahastasana, Bridge pose/Setubandasana, Thunderbolt/Vajrasana, Locust pose/Shalabasana, Sitting forward - fold/Paschimottasana, Camel pose/Ustrasana, Noose pose/Pasasana, Pranayama.

\section{METHODOLOGY}

For the purpose of investigating awareness trends in Indian women a survey was conducted on 305 females from different states (e.g. Jammu \& Kashmir, Haryana, Telangana, Karnataka, Delhi, Rajasthan etc.) aged between 14-31 years. The subjects were asked to write what do they understand by PMS and their level of their awareness was assessed based on the responses provided. 


\section{RESULTS AND DISCUSSION}

\section{What do you understand by PMS ?}

no Answer $\square$ Inapproprate Answer $\quad$ Correct Answer

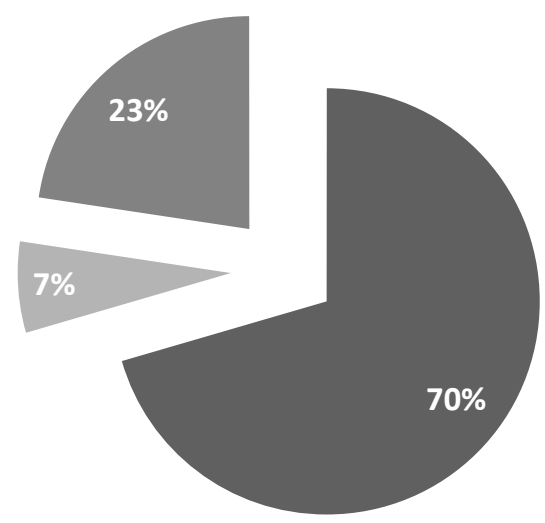

Out of 305 females, $70 \%$ did not answer, $7 \%$ gave inappropriate answer and $23 \%$ were able to correctly answer to the given question.

\section{CONCLUSION}

"It is okay to talk about menstruation. Regular menstruation is a sign of good health not a curse of God"

It has never been acceptable to speak about menstruation in India, as it has from time memorable been considered as a taboo. The lack of awareness on this aspect not only leads to lack of skills to manage discomfort, or hygiene matters, but also lowers the confidence level of women. It is high time that women start accepting and discussing about menstruation as it is a natural process, and accept it as a sign of good health and not a curse. In today's world it is very easy to get any information through technology, making it easier for women who are unable to discuss such issues with other members of the society to gain clarity and knowledge on how to manage unspoken issues like menstruation in between the four walls of their homes or workplace. Here, the ancient art of yoga plays a vital role by making it even more convenient for women to harmonise the psycho-physiological trauma they undergo before, during and after menstruation as it can be practised anywhere be it the privacy of a room, with a group of friends and family or a session with a trainer. Indulging in physical activities such as swimming, cycling, running, yoga etc. can be helpful in bringing about a balance in the mind and body of an individual, sometimes to an extent that it can eliminate the need to depend on medications to overcome menstrual sickens. 


\section{A Survey Exploring PMS Awareness Trends in Indian Women and a Review of Ways to Harmonize Psycho - Physiological Stress of Premenstrual Syndrome Practicing Yoga Asanas}

\section{REFERENCES}

Abc-of-yoga.com,. (2016). Yoga for PMS (Pre-menstrual Syndrome) and Menstrual Cramps. Retrieved 10 February 2016, from http://www.abc-of-yoga.com/yoga-and-health/yogafor-dysmenorrhea-and-pms.asp

Artofliving.org,. (2016). Yoga : What Is Yoga?. Retrieved 10 February 2016, from http://www.artofliving.org/in-en/yoga

Artofliving.org,. (2016). Yoga for Pre-Menstrual Syndrome \& Menstrual Pain. Retrieved 10 February 2016, from http://www.artofliving.org/yoga/yoga-for-women/pms-painyoga?mobile $=1$

Guterman, M., Mehta, P., \& Gibbs, M. (2007). Internet Scientific Publications. Ispub.com. Retrieved 10 February 2016, from http://ispub.com/IJWH/5/2/8213

Guterman, M., Mehta, P., \& Gibbs, M. (2007). Menstrual Taboos Among Major Religions. The Internet Journal Of World Health And Societal Politics, 5(2). Retrieved from http://ispub.com/IJWH/5/2/8213\#

Stages of development.(2016).

http://png.clipart.me/graphics/previews/270/woman-stages-of-development_27056038.jpg

Stappler, M., \& Cunha, J. (2014). Premenstrual Syndrome (PMS) Causes, Symptoms, Treatment - Premenstrual Syndrome (PMS) Symptoms - eMedicineHealth. eMedicineHealth. Retrieved 10 February 2016, from http://www.emedicinehealth.com/premenstrual_syndrome_pms/page3_em.htm Worldlibrary.org,. (2002). Premenstrual Syndrome. Retrieved 10 February 2016, from http://www.worldlibrary.org/articles/premenstrual_syndrome

\section{Figure Credit}

Art of Living,. (2016). Retrieved from http://cdn.artofliving.org/sites/www.artofliving.org/files/wysiwyg_imageupload/Yoga_P MS_03.jpg http://cdn.artofliving.org/sites/www.artofliving.org/files/wysiwyg_imageupload/Yoga_P MS_02.jpg http://cdn.artofliving.org/sites/www.artofliving.org/files/wysiwyg_imageupload/Yoga_P MS_04.jpg http://cdn.artofliving.org/sites/www.artofliving.org/files/wysiwyg_imageupload/Yoga_P MS_05.jpg http://cdn.artofliving.org/sites/www.artofliving.org/files/wysiwyg_imageupload/Yoga_P MS_06.jpg http://cdn.artofliving.org/sites/www.artofliving.org/files/wysiwyg_imageupload/Yoga_P MS_01.jpg 